Dhaka Univ. J. Biol. Sci. 19(2): 195-201, 2010 (July)

\title{
SURVIVAL STUDY OF ESCHERICHIA COLI O157:H7 IN AQUATIC SYSTEM OF BANGLADESH
}

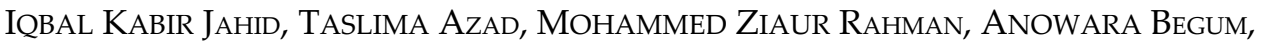 \\ SIRAJUL ISLAM KHAN AND HUMAIRA AKHTER* \\ Department of Microbiology, University of Dhaka, Dhaka-1000, Bangladesh
}

Key words: E. coli O157:H7, Aquatic system, Survival study

\begin{abstract}
The survival pattern of Escherichia coli O157:H7 was observed in laboratory microcosm with different sources of surface and drinking water using the green fluorescent protein (GFP) as a genetic marker. The water quality was monitored on the basis of bacteriological and physico-chemical parameters. The untreated and filtered water were inoculated with the genetically transformed E. coli O157:H7. The survival pattern was determined by drop plate method observing the green fluorescence of the E. coli O157:H7 colonies under UV light. The survival of E. coli O157:H7 decreased in most of the untreated saline and waste water and higher survival was observed in pond and tap water. The E. coli O157:H7 survived more than 23 days in tap and pond water and less than 20 days in sea, estuarine and waste water. The fluorescent microscopic findings revealed the VBNC state of E. coli O157:H7. The study conclusively proved that the better survival of E. coli O157: H7 depends on the quality of water.
\end{abstract}

\section{Introduction}

Enterohemorhagic Escherichia coli O157:H7 is a human pathogen with a very low infectious dose which can cause non-bloody diarrhoea to bloody diarrhoea leading to severe and sometimes fatal illnesses such as haemorrhagic colitis and haemolytic uraemic syndrome $^{(1)}$ especially in children. It has been associated with different kinds of water like surface water.(2) Rangel et al.(3) also found that 31 outbreaks being waterborne with 21 from recreational water of which lakes or ponds were responsible for $67 \%$ of the recreational outbreaks and swimming pools for 33\%; 10 outbreaks from drinking water which were attributed to three nonchlorinated municipal water systems, a local well water system, a residential faucet and ice through cross contamination. The contamination by the E. coli O157:H7 was also detected in private water supply in Netherlands $s^{(4)}$ and rural water (both surface and groundwater) drinking water supplies in India. (5)

E. coli $\mathrm{O} 157: \mathrm{H7}$ has been found to persist in the environment for days to weeks depending on environmental conditions.(6) Survival of E. coli O157:H7 in surface waters was found to be higher at lower temperatures and two to three times greater in river and lake sediments at the same temperatures. In ground water, survival of 15 days was

*Corresponding author: E-mail: nhsks123@yahoo.com 
observed in the previous findings. In water contaminated with manure, E. coli O157:H7 was observed to survive at outside ambient temperatures for 92 days.(7)

The survival characteristics of E. coli O157: $\mathrm{H} 7$ have been detected using lux gene and GFP as genetic marker, in several studies related to soil, drinking water, lettuce plants and manure.(8) Therefore, we investigated the E. coli O157:H7 survival in the laboratory microcosms using water from different sources, which could represent the real environmental conditions.

\section{Materials and Methods}

Escherichia coli O157:H7 (NCTC 12079) strain was used in this study. The strain was genetically modified by inserting plasmid (pGLO, BioRad, USA) encoding araC induced synthesis of protein that fluoresce green (GFP) when illuminated with 365-nm wavelength ultraviolet (UV) light and also showed resistance to ampicillin.

Competent E. coli O157:H7 cells were prepared according to the protocol described by BioRad. The competent cells were then electroporated in a Gene Pulser II (Bio-Rad) with plasmid vector pGLO (BioRad, USA), and an electrical pulse (T 1.7 msec) was applied at $2.5 \mathrm{kV}$ and $25 \mu \mathrm{F}$ with the pulse controller adjusted to $200 \Omega$. Transformants were selected from isolated colonies grown on Luria-Bertani (LB) plates containing 100 $\mathrm{mg}$ of ampicillin/ml and arabinose (5\%). The plasmid makes it possible to count colonies of the test bacteria in the presence of a large indigenous microflora on media containing ampicillin $(100 \mathrm{mg} / \mathrm{l})$.

A loopful of freshly cultured E. coli isolates was suspended in the $250 \mathrm{ml}$ conical flask containing $100 \mathrm{ml}$ of lactose broth. After overnight incubation at $25^{\circ} \mathrm{C}$, the culture medium was centrifuged (Eppendorf, USA) at $1000 \mathrm{rpm}$ for $10 \mathrm{~min}$. After discarding the supernatant, the cell pellets were washed with phosphate buffered saline (PBS). The cells were then resuspended in $10 \mathrm{ml}$ of normal saline. It was then vortexed to prepare a homogenous cell suspension. The absorbance of the suspension at $\mathrm{A}_{600}$ was set at 0.05 with a spectrophotometer to prepare the desired concentration of cell suspension to about $10^{7} \mathrm{cells} / \mathrm{ml}$. The same inoculum concentrations were used for the three series of microcosm analysis.

The total dissolved solids (TDS), conductivity, salinity were measured using portable meters (HACH Conductivity Meter, Cat. No. 51800-18; MA, USA) and pH was measured using pH indicator stick (Cat No. FB33003, Fisherbrand, UK).

All the conical flasks $(250 \mathrm{ml})$ were initially washed by $0.1 \mathrm{~N} \mathrm{HCl}$ and then with deionized water. Then all flasks were autoclaved and cooled to prepare for microcosm. Water was aseptically collected from Cox's Bazar (saline), Chittagong (estuary), Dhaka (tannery, surface pond water, tap water) in sterile Nalgene plastic bottles. Ten water samples designated as Sample-1 (Cox's Bazar unfiltered water), Sample-2 (Cox's Bazar filtered water), Sample-3 (Chittagong unfiltered water), Sample-4 (Chittagong filtered 
water), Sample-5 (Tap unfiltered water) and Sample-6 (Tap filtered water), Sample-7 (Tannery unfiltered water), Sample-8 (Tannery filtered water), Sample-9 (Shahidullah Hall pond unfiltered water) and Sample-10 (Shahidullah Hall pond filtered water) were used for preparation of microcosoms, respectively. Background levels of E. coli and E. coli O157:H7 were established using membrane filtration of water and subsequent incubation of the SMAC agar. Water sample microcosms $(250 \mathrm{ml}$ each) were prepared from unfiltered and filtered (with both $3 \mathrm{Wm}$ and $0.22 \mu \mathrm{M} \mathrm{Wm}$ ) source water, which received additions of E. coli O157:H7 strain 12079 containing GFP plasmid to a density of $10^{9}$ colony forming units $\left(\mathrm{Cfu} / \mathrm{ml}\right.$. The microcosms were incubated at $37^{\circ} \mathrm{C}$.

A $0.1 \mathrm{ml}$ sample of filtered and unfiltered water was mixed with $0.9 \mathrm{ml}$ of sterile normal saline on a vortex mixer. A tenfold dilution was prepared in sterile, normal saline and surface-plated on LB agar containing ampicillin and arabinose. Colonies were counted after $24 \mathrm{hr}$ incubation at $37^{\circ} \mathrm{C}$ and recorded by observing their fluorescent green color under the UV lights. The counts were expressed as $\log _{10} \mathrm{Cfu} / \mathrm{ml}$.

Samples were further examined by epifluorescent microscopy on days after nonculturable state. Mounted on glass microscope slides and examined with an Olympus BH-2 epifluorescent microscope equipped with a 40× objective lens; images were captured with camera attached to microscope and formatted using Adobe Photoshop.

\section{Result and Discussion}

The Figs. 1(A,B) show the transformed colony of E. coli O157:H7 with GFP plasmid. The green fluorescent color under UV light indicated that E. coli O157:H7 contain the GFP plasmid. Transformation efficiency of E. coli O157:H7 was calculated as $3 \times 10^{-7} \mathrm{Cfu} / \mathrm{ml}$.
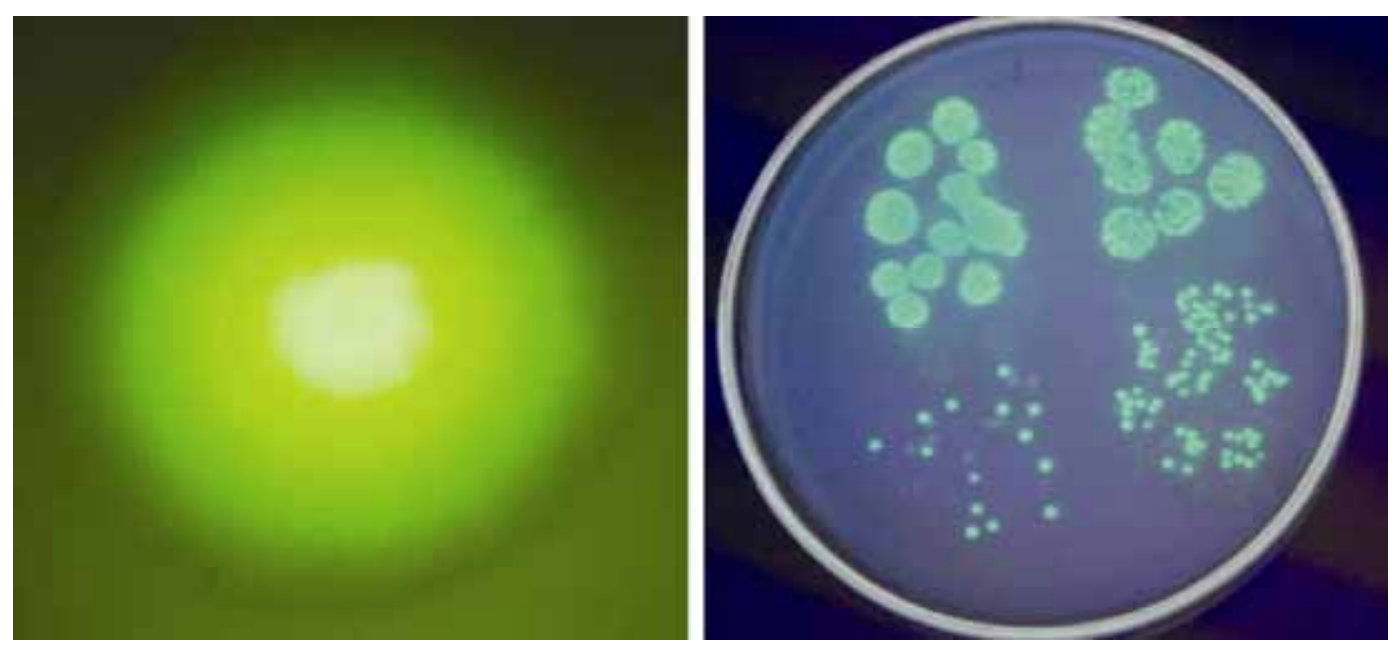

Fig. 1. Transformed colony of E. coli O157:H7 with GFP (A) and Plate showing the GFP positive and other negative colony (B). 
The Table 1 shows the results of bacteriological and physico-chemical parameters of the water used for the study of E. coli O157:H7 survival. It was found that all the water samples were free from E. coli O157:H7 but all samples were contaminated by E. coli except in tap water. The physico-chemical analyses showed that environmental water samples were close to neutral or slightly alkaline ( $\mathrm{pH}$ in the range of 7.10 to 9.5). TDS of water varied between $29.9 \mathrm{mg} / \mathrm{l}$ tap water and $145 \mathrm{~g} / \mathrm{l}$ in tannery waste. The conductivity was $24.6 \mathrm{~ms} / \mathrm{cm}$ in Shahidullah Hall pond water and highest $(292 \mathrm{~ms} / \mathrm{cm})$ was found in Tannery waste (Table 1). The highest salinity was observed in Cox's Bazar sea water and lowest in tap water (Table 1).

Table 1. The bacteriological and physico-chemical parameters of different aquatic system.

\begin{tabular}{lcccccc}
\hline $\begin{array}{l}\text { Water } \\
\text { sources }\end{array}$ & E. coli & E. coli O157:H7 & $\mathrm{pH}$ & $\begin{array}{c}\text { Salinity } \\
(\%)\end{array}$ & $\begin{array}{c}\text { Conductivity } \\
(\mathrm{ms} / \mathrm{cm})\end{array}$ & $\begin{array}{l}\text { TDS } \\
(\mathrm{g} / \mathrm{l})\end{array}$ \\
\hline $\begin{array}{l}\text { Cox's Bazar } \\
\text { Sea water }\end{array}$ & $1.2 \times 10^{1}$ & 00 & 7.5 & 34 & 51.7 & 25.8 \\
$\begin{array}{l}\text { Chittagong } \\
\text { Estuarine water }\end{array}$ & $1.1 \times 10^{1}$ & 00 & 7.6 & 18.9 & 30.4 & 15.21 \\
$\begin{array}{l}\text { Shahidullah } \\
\text { Hall pond water }\end{array}$ & $1.0 \times 10^{5}$ & 00 & 7.1 & 0.1 & 24.6 & 145.7 \\
$\begin{array}{l}\text { Tannery water } \\
\text { Tap water }\end{array}$ & $1.25 \times 10^{3}$ & 00 & 9.5 & 14.9 & 292 & 145 \\
\hline
\end{tabular}

The Figs. 2 and 3 show the survival of E. coli O157:H7 observed in different sources and treated water. In the surface water, E. coli O157:H7 declined most rapidly in the untreated microcosm rather than in filtered water microcosms. Survival of the isolates in filtered water from Cox's Bazar, Chittagong and Tannery was found to be significantly higher after 7, 9 and 13 days of incubation, respectively as compared to the untreated water. No culturable colony was recovered on days 11, 13, 18 and 20 for untreated and filtered Cox's Bazar water, untreated and filtered Chittagong water, respectively. The survival in Tannery waste was also higher than that of Cox's Bazar sea water and no culturable colony was found on the days 13 and 19 in untreated and filtered water of tannery. In the Shahidullah Hall pond water, E. coli O157:H7 survived longer and a strong correlation was found between the filtered water and untreated water. The significant difference between untreated and filtered water was observed from day 5 and until the experiments were completed. Again there was no significant difference observed in the tap water culture, in comparison to the filtered and untreated water at any time point of the experiment. 
The Fig. 4 represents the microscopic observation of E. coli O157:H7 in the laboratory microcosm when no culturable colony was found from different water samples on the culture medium. The fluorescent microscopy revealed some fluorescent colony which might be explained that the cells were still viable but non-culturable on conventional culture medium.
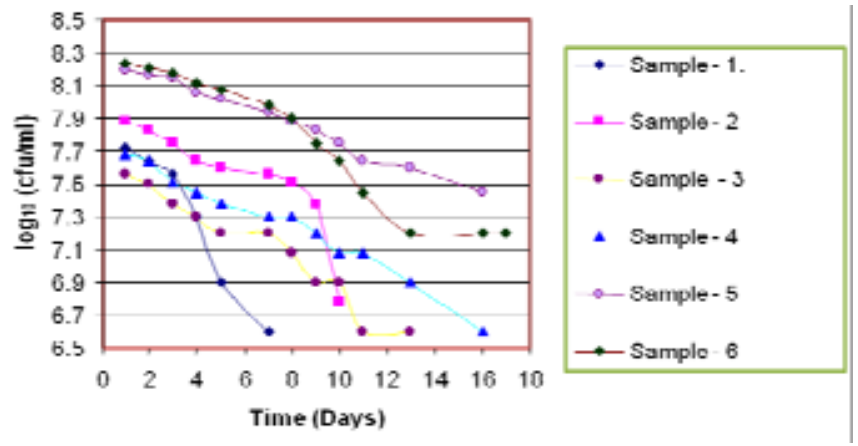

Fig. 2. Showing survival of E. coli in waters from Cox's Bazar, Chittagong and Tap water with and without filter effect.

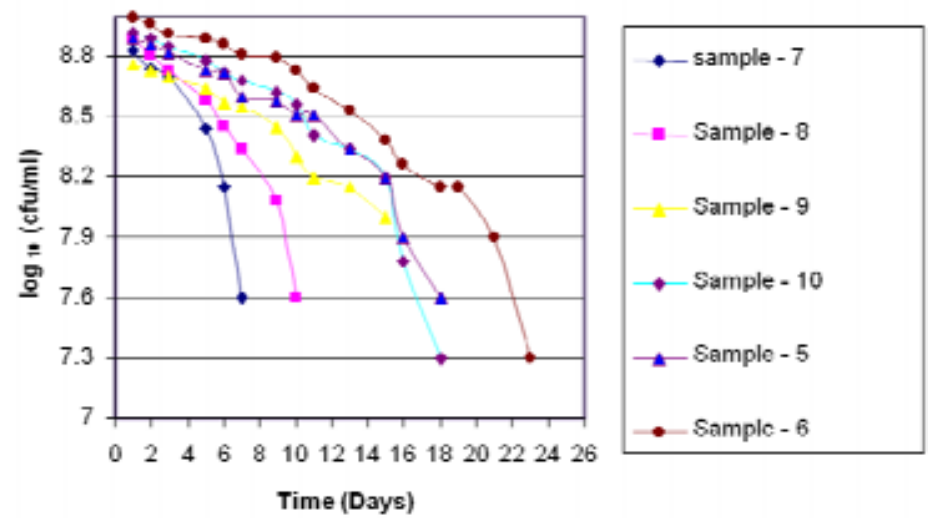

Fig. 3. Showing survival of E. coli in waters from Tannery water, Shahidullah Hall pond water and Tap water with and without filter effect.

Survival has been defined as the maintenance of viability under adverse environmental circumstances. The growth of aquatic microorganisms is affected by a great variety of physical and chemical factors, which in multiple ways may act with or against one another. Various biological, chemical and physical stresses influence the survival of E. coli in soils, such as high and low temperatures, limited moisture, low organic matter, high salinity, competition and predation. Based on these various results that have already been documented it could be hypothesized that bacterial cells have the ability to survive or adapt differently to a new stressful environment. 
The present study investigated the survival of genetically modified (pGFPtransformed) laboratory strains of E. coli O157:H7 under aerobic condition with different types of water. An exponential linear destruction was observed for Escherichia coli O157:H7 and Salmonella typhimurium in cattle manure and manure slurry stored at 4, 20 or $37^{\circ} \mathrm{C}$ using GFP as marker ${ }^{(9)}$. Escherichia coli O157:H7 cells survived for up to 77, > 226, and 231 days in manure-amended autoclaved soil held at 5, 15 , and $21^{\circ} \mathrm{C}$, respectively and the study was done using GFP marker.(10)

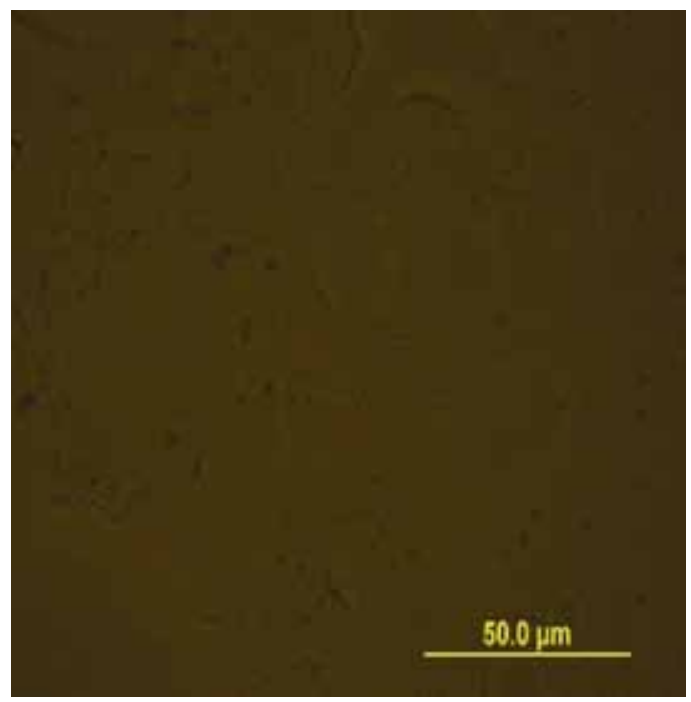

Fig. 4. Microscopic observation of E. coli O157:H7 under fluorescent microscopy in viable but nonculturable state.

The results of the present study demonstrated that long survival in pond and tap water is possibly due to quality of water which was found to be better than the other water samples (Table 1). The physico-chemical parameters also correlated with the survival results. McGee et al.(7) found that E. coli O157:H7 can survive in farm water under field and shed conditions at temperatures less than $15^{\circ} \mathrm{C}$ for up to 24 days. E. coli O157:H7 was inoculated into well water from four different sites in the north east of Scotland in untreated, filtered and autoclaved water and a long survival time up to 70 days was observed. The significant difference among filtered water of all the samples except tap water indicated that presence of other microscopic organism that may have an effect on E. coli O157:H7. ${ }^{(11,12)}$ The insignificant difference of survival in tap water might be due to absence of predator in that water. The most important factors for long-term survival and same survival rate of both untreated and filtered water indicated to be the absence of protozoan grazing populations and low concentrations of heavy metals.

The rate of decline of the counts of E. coli O157:H7 was demonstrated in viable but nonculturable (VBNC) state of E. coli O157:H7. To determine the viable but non- 
culturable state of bacteria, luminescence has been previously used by Duncan et al.(13) and later by Artz and Killham. ${ }^{12)}$ In this study we also determined the viable but nonculturable state by using epifluorescence technique.

The present study suggested that salinity, predator and other parameters are responsible for the short duration of E. coli O157:H7 in different sources of water.

\section{References}

1. Jones DL 1999. Potential health risks associated with the persistence of Escherichia coli O157:H7 in agricultural environments. Soil Use Manage 15: 76-83.

2. Olsen SJ, G Miller, T Breuer, M Kennedy, C Higgins, J Walford, G McKee, K Fox, W Bibb and P Mead 2002. A waterborne outbreak of Escherichia coli O157:H7 infections and hemolytic uremic syndrome: implications for rural water systems. Emerg. Infect. Dis. 8: 370-375.

3. Rangel JM, PH Sparling, C Crowe, PM Griffin and DL Swerdlow 2005. Epidemiology of Escherichia coli O157:H7 outbreaks, United States, 1982-2002. Emerg. Infect. Dis. 11: 603609.

4. Schets FM, M During, R Italiaander, L Heijnen, SA Rutjes, WK van der Zwaluw and AM de Roda Husman 2005. Escherichia coli O157:H7 in drinking water from private water supplies in the Netherlands. Water Res. 39: 4485-4493.

5. Ramteke PW and S Tewari 2007. Serogroups of Escherichia coli from drinking water. Environ. Monit. Assess. 130: 215-20.

6. Williams AP, LM Avery, K Killham and DL Jones 2007. Persistence, dissipation, and activity of Escherichia coli O157:H7 within sand and seawater environments. FEMS Microbiol. Ecol. 60: 24-32.

7. McGee P, DJ Bolton, JJ Sheridan, B Earley, G Kelly and N Leonard 2002. Survival of Escherichia coli O157:H7 in farm water: its role as a vector in the transmission of the organism within herds. J. Appl. Microbiol. 93: 706-713.

8. Solomon EB, S Yaron and KR Matthews 2002. Transmission of Escherichia coli O157:H7 from contaminated manure and irrigation water to lettuce plant tissue and its subsequent internalization. Appl. Environ. Microbiol. 68: 397-400.

9. Himathongkham S, S Bahari, H Riemann and D Cliver 1999. Survival of Escherichia coli O157:H7 and Salmonella typhimurium in cow manure and cow manure slurry. FEMS Microbiol. Lett. 178: 251-257.

10. Jiang X, J Morgan and MP Doyle 2002. Fate of Escherichia coli O157:H7 in Manure-amended Soil. Appl. Environ. Microbiol. 68: 2605-2609.

11. Mead PS and PM Griffin 1998. Escherichia coli O157:H7. Lancet. 352: 1207-1211.

12. Artz RR and K Killham 2002. Survival of Escherichia coli O157:H7 in private drinking water wells: influences of protozoan grazing and elevated copper concentrations. FEMS Microbiol. Lett 216: 117-122.

13. Duncan S, LA Glover, K Killham and JI Prosser 1994. Luminescence-based detection of activity of starved and viable but nonculturable bacteria. Appl. Environ. Microbiol. 60:1308-1316. 